\title{
Predictors of misreporting in an elderly population: the 'Quality of life after 65' study
}

\author{
C Bazelmans ${ }^{1, *}$, C Matthys ${ }^{2}$, S De Henauw² ${ }^{2}$ M Dramaix', M Kornitzer ${ }^{1}$, \\ $G$ De Backer ${ }^{2}$ and A Levêque ${ }^{1}$ \\ 'Department of Epidemiology \& Health Promotion, School of Public Health, Université Libre de Bruxelles, \\ 808 Route de Lennik, B-1070 Brussels, Belgium: ${ }^{2}$ Department of Public Health, Ghent University, Ghent, Belgium
}

Submitted 1 August 2005: Accepted 9 May 2006

\begin{abstract}
Objectives: To evaluate the prevalence and identify some predictors of misreporting in an elderly Belgian population and to assess the effect of underreporting on estimated intakes of macronutrients and foods.

Design: A 1-day food record was completed by 2083 adult men and women aged 65 years or more. Individuals whose energy intake was lower than $0.90 \times$ BMR (basal metabolic rate) were defined as underreporters. Overreporting was defined as energy intake greater than $2 \times$ BMR.

Results: Underreporting and overreporting occurred in $13.6 \%$ and $7.9 \%$ of food records, respectively. Results from logistic regression models indicated that gender and body mass index (BMI) were predictors of misreporting. Whereas women were more likely to underreport energy intake, the prevalence of overreporting was higher in men. Underreporting was more prevalent among obese people and overreporting more prevalent in normal-weight subjects. Smoking status and education level did not predict underreporting; however, overreporting was more likely to occur in more highly educated subjects. A cultural difference in reporting of nutrient intakes was also found, with the percentage of underreporters being higher among Walloons compared with Flemish.

Conclusion: BMI seemed to be one of the most important factors in misreporting. This calls for special attention when dietary surveys are performed on obese or lean people.
\end{abstract}

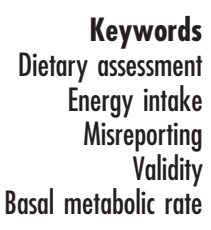

The measurement of nutrient intake in dietary surveys represents a methodological challenge. This measurement sometimes relies on self-reports of food intake over varying periods of time. The most widely used methods are dietary recalls, where subjects report on foods consumed over the previous 24 hours; diet diaries, in which subjects record all food consumed on a daily basis; and food-frequency questionnaires, which require subjects to report food consumption patterns over times ranging from one month to one year or more. Because all dietary methods have their limitations, none of these can be considered a 100\% reliable reference measure for assessing dietary intake. Therefore, biological markers of food intake have been sought in order to validate selfreported energy intake by objective measures ${ }^{1-5}$. The doubly labelled water technique is an example of a biomarker that can be used to validate self-reported energy intake ${ }^{1-4}$. This technique is used to measure energy expenditure in free-living subjects and is currently considered the 'gold standard' for the measurement of total energy expenditure in humans. Comparing measured energy expenditure with reported energy intake gives an idea of the degree of misreporting in a dietary survey.
All mentioned dietary methods are prone to under- or/and overreporting of energy intake ${ }^{6}$. This misreporting may result from difficulties in accurately reporting food consumption and portion size, changing eating patterns or overestimating consumption of more socially desirable foods, etc. ${ }^{7}$. Because the doubly labelled water technique is too complex and costly to be used in large epidemiological studies, alternative methods have been developed. One of these is the concept of cut-off values developed by Goldberg et $a l^{5}$ and based on the ratio between observed energy intake and estimated basal metabolic rate $\left(\mathrm{EI} / \mathrm{BMR}_{\mathrm{est}}\right)$ for a specified energy expenditure level (physical activity level, PAL).

The existence of under- and overreporting of energy intake may seriously distort the interpretation of results in dietary studies or obscure diet-disease relationships ${ }^{8-10}$. Prentice $^{9}$ has argued that the lack of a relationship between dietary fat and breast cancer may be a result of non-systematic underreporting of fat and energy intake.

Underreporting is a well documented concern. A large number of studies show that the extent of underreporting varies among individuals ${ }^{11-17}$. Reporting of low energy intake is frequently observed and more likely to occur 
among women ${ }^{17-19}$, obese individuals ${ }^{13-19}$, subjects younger than 18 and older than 65 years ${ }^{14,17,18}$ and in various ethnic groups ${ }^{15}$. Some studies have found cultural differences in dietary reporting behaviours ${ }^{14,15}$. Fewer studies have examined energy overreporting and found that it is more likely to occur among lean and more educated subjects ${ }^{18}$. To our knowledge, no studies have specifically examined the extent of under- and overreporting among the elderly in Belgium.

The aims of the present study were to evaluate the prevalence and identify some predictors of under- and overreporting in an elderly Belgian population and to assess the effect of misreporting on the estimated intakes of macronutrients and foods.

\section{Materials and methods}

\section{Study population}

The data used for the present analyses come from the 'Quality of life after 65' study. The population of this study was selected from participants in the Belgian Interuniversity Research on Nutrition and Health (BIRNH), carried out between 1979 and 1984 within a random sample stratified by age and sex and representative of the Belgian population from the ages of 25 to 74 years. The methodology of the BIRNH study has been presented in detail elsewhere ${ }^{20}$.

Ten years after the BIRNH study, former respondents aged 65 years or more on 1st January $1994(n=4446)$ were invited to participate in a new survey, the 'Quality of life after $65^{\prime}$ study. Of the 4446 subjects, 28\% had died, 3\% were lost to follow-up and 3045 were living. From these, $11 \%$ were in a medical institution and excluded from the survey, and a further 26\% refused to participate in the study. The final study sample comprised 2083 subjects (participation rate of $49.5 \%$ ).

The aims of the 'Quality of life after 65' study were to measure chronic morbidity, invalidity and mortality in a cohort of elderly subjects.

\section{Data collection}

In the current study two contact points were foreseen. During the first contact, all subjects received a standardised, structured questionnaire that was to be selfadministered at home. This questionnaire surveyed lifestyle (including smoking status) and socio-economic characteristics (age, gender, education level), and contained a semi-structured food diary in which the dietary intake of the subject was assessed by a 1-day estimated food record. Respondents were informed about the aim of the study and were given necessary instructions for accurate completion of the food diary. Special attention was given to the issue of portion size of food items. Information on the type (including brand names) and amount of foods consumed was collected through an open entry format. For each eating occasion, the time of day was recorded. During the second contact the participants came to the survey centre, where all questionnaires were checked and verified by trained, experienced dietitians. At the same time body weight was measured according to standardised methods recommended by the World Health Organization (WHO) ${ }^{21}$.

The amount of food items was quantified by using standardised methods to assign weights or volumes to certain amounts of food. The conversion of food items into nutrients was based on the Dutch and Belgian food composition tables ${ }^{22,23}$.

\section{Evaluation of under-and overreporting}

The ratio $\mathrm{EI} / \mathrm{BMR}_{\mathrm{est}}$, described by Goldberg et al. ${ }^{5}$, was used to estimate the prevalence of under- and overreporting of energy intake. For individuals with a normal (not bed-bound) lifestyle, EI/BMR est ratio of 1.35 is considered to indicate the lowest value for habitual energy intake. For an individual the cut-off value for probable underreporting depends on the number of days the survey covers, the value of $\mathrm{BMR}_{\text {est }}$ and the lower limit of the $95 \%$ confidence interval (CI). BMR est was obtained by the Schofield equation ${ }^{24}$ based on age, gender and body weight. The ratio was then compared with Goldberg et al.'s cut-off for plausible energy intake, depending on the sample size and number of days. With a 1-day dietary record, the minimum plausible energy intake at the individual level occurs at EI/BMR ${ }_{\text {est }}=0.90$. At group level, the cut-off value for probable underreporting is estimated at $\mathrm{EI} / \mathrm{BMR}_{\mathrm{est}}=1.53$. Overreporting was defined as EI/ $\mathrm{BMR}_{\text {est }}>2^{24,25}$. Others studies have defined overreporting as EI/BMR est $>2.4^{18,19}$, the maximum for a very active lifestyle in a general population. However, people aged 65 years and over have lower energy expenditure than younger adults, and Black et al. ${ }^{25,26}$ consider that $\mathrm{PAL}>2.0$ is rare in this relatively inactive sample.

\section{Statistical analysis}

Statistical analyses were carried out using SPSS software, version 10 (SPSS Inc., 1999). Usual descriptive statistics were computed for the variables taken into account in the analysis. The potential predictors of underreporting (lowenergy reporters, LER) and overreporting (high-energy reporters, OER) taken into account were age, gender, educational level, smoking status, body mass index (BMI) and cultural origin. Means and standard deviation (SD)

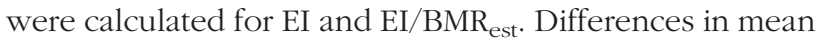
values of $\mathrm{EI}$ and $\mathrm{EI} / \mathrm{BMR}_{\text {est }}$ between predictors were tested using the $t$-test for independent samples and analysis of variance. The prevalence of LER and OER was also compared using Pearson's chi-square test. Logistic regression analyses were used to examine predictors of LER and OER controlling for potential covariates. The variables finally included in the models were selected step-by-step using a backward procedure. Odds ratios (OR) and their 95\% CI were derived from the different logistic regression models. Adequacy of the logistic 
regression models was checked by residual analysis and application of the Hosmer-Lemeshow goodness-of-fit test. Mean nutrient and food intakes (absolute intake and intake expressed as a percentage of total energy) of misreporters (LER and OER) and accurate reporters were compared using the non-parametric Mann-Whitney test for independent samples. A $P$-value of $<0.05$ was taken as the threshold for significance.

The number of respondents presented in the tables varies owing to missing values.

\section{Results}

The general characteristics of the study population are described in Table 1. The respondents comprised 1126 men and 957 women with a mean (SD) age of 74.4 (5.6) years. More than $60 \%$ of the subjects were Flemish and a majority had low education level. The prevalence of current smokers was $42 \%$ and almost $20 \%$ of the subjects were obese according to the WHO definition of obesity.

Table 1 also presents $\mathrm{EI}$ and $\mathrm{EI} / \mathrm{BMR}_{\mathrm{est}}$ according to demographic and lifestyle characteristics. Mean (SD) EI for the total population was 1948 (738) $\mathrm{kcalday}^{-1}$ and was significantly higher in men. EI decreased significantly with age. Significant differences in EI were observed across categories of BMI and education level: EI decreased as BMI increased and increased as education level increased. Non-smokers had significantly lower EI. No difference in EI was seen according to cultural origin.

Mean (SD) EI/BMR est was 1.37 (0.50), below the acceptable limit of 1.53 defined by Goldberg et al. ${ }^{5}$, indicating that EI was underreported in the group as a

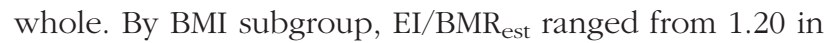
obese subjects $\left(\mathrm{BMI} \geq 30 \mathrm{~kg} \mathrm{~m}^{-2}\right.$ ) to 1.51 in normalweight subjects (BMI $<25 \mathrm{~kg} \mathrm{~m}^{-2}$ ). Significant differences in $\mathrm{EI} / \mathrm{BMR}_{\text {est }}$ were observed by gender, smoking status and BMI: the ratio was significantly lower among females, nonsmokers and obese subjects. Mean EI/BMR ${ }_{\text {est }}$ was also slightly lower among Walloons, oldest subjects ( $\geq 85$ years) and respondents with a low education level; however these differences were not significant.

\section{Extent of misreporting}

The prevalence of misreporting in our sample was 22\%. More than $70 \%(n=1626)$ of the subjects reported their energy intake plausibly.

Using EI/BMR ${ }_{\text {est }}<0.90$ as the cut-off to classify LER and $\mathrm{EI} / \mathrm{BMR}_{\mathrm{est}}>2$ to define OER, underreporting occurred in $13.6 \%(n=293)$ and overreporting in $7.9 \%(n=164)$ of food records. The prevalence of LER differed significantly by gender, education level, smoking status and BMI, being highest in females, non-smokers, those with low education level and those with high BMI. LER prevalence was also higher in Walloons compared with Flemish, but the difference was not significant (Table 2). The prevalence of OER differed significantly by gender, education level and BMI, being higher in males, those with high education level and those with low BMI (Table 2).

Logistic regressions employing respectively $\mathrm{EI} / \mathrm{BMR}_{\mathrm{est}}<0.90$ and $\mathrm{EI} / \mathrm{BMR}_{\text {est }}>2$ as dependent variable and age, gender, smoking status, cultural origin, education level and BMI as independent variables

Table 1 Sociodemographic and lifestyle characteristics of respondents, and reported El and $\mathrm{El} / \mathrm{BMR}_{\mathrm{est}}$ by demographic and lifestyle characteristics

\begin{tabular}{lccccc}
\hline Characteristic & Value & El (kcal day $\left.{ }^{-1}\right)$ & $P$-value & El/BMR est & $P$-value \\
\hline Gender $(n=2083)$ & & & & & \\
$\quad$ Male & 54.1 & $2179(769)$ & $<0.001^{*}$ & $1.42(0.52)$ & $<0.001^{*}$ \\
$\quad$ Female & 45.9 & $1678(597)$ & & $1.30(0.48)$ & \\
Age (years) $(n=2083)$ & $74.4(5.6)$ & & & \\
$\quad<75$ & 59.6 & $2039(814)$ & $<0.001 \dagger$ & $1.35(0.50)$ & $0.44 \dagger$ \\
$\quad 75-84$ & 35.4 & $1979(685)$ & & $1.37(0.54)$ & \\
$\quad \geq 85$ & 4.9 & $1866(726)$ & & $1.31(0.42)$ & \\
Cultural group $(n=2083)$ & & & & \\
$\quad$ Flemish & 61.3 & $1961(682)$ & $0.26^{*}$ & $1.38(0.47)$ & $0.12^{*}$ \\
$\quad$ Walloon & 38.7 & $1926(822)$ & & $1.35(0.55)$ & \\
Education level $(n=2075)$ & & & & \\
$\quad$ Elementary & 56.9 & $1902(753)$ & $0.002 \dagger$ & $1.34(0.52)$ & $0.07 \dagger$ \\
$\quad$ Secondary & 37.0 & $2000(710)$ & & $1.39(0.48)$ & \\
$\quad$ Upper studies & 6.1 & $2073(734)$ & & $1.41(0.55)$ & \\
Smoking status $(n=2041)$ & & & & \\
$\quad$ Smoker & 42.2 & $2132(789)$ & $<0.001 \dagger$ & $1.41(0.53)$ & $<0.001 \dagger$ \\
$\quad$ Ex-smoker & 5.3 & $2151(657)$ & & $1.40(0.45)$ & \\
$\quad$ Non-smoker & 52.5 & $1786(663)$ & & $1.33(0.49)$ & \\
BMI (kg m $\left.{ }^{-2}\right)(n=2068)$ & $27.0(4.0)$ & & & \\
$\quad<25$ & 35.5 & $2040(779)$ & $<0.001 \dagger$ & $1.51(0.56)$ & $<0.001 \dagger$ \\
$\quad 25-29$ & 45.2 & $1931(689)$ & & $1.34(0.45)$ & \\
$\quad \geq 30$ & 19.3 & $1860(783)$ & & $1.20(0.49)$ & \\
\hline
\end{tabular}

El - energy intake; $\mathrm{BMR}_{\text {est }}$ - estimated basal metabolic rate; $\mathrm{BMI}$ - body mass index.

Data presented as mean (standard deviation) or \%.

${ }^{*} P$-values derived using the $t$-test for independent samples.

$\dagger P$-values derived by analysis of variance. 
Table 2 Prevalence of under- and overreporting by demographic and lifestyle characteristics

\begin{tabular}{|c|c|c|c|c|}
\hline & $\begin{array}{l}\text { LER (\%) } \\
(n=293)\end{array}$ & $P$-value* & $\begin{array}{l}\text { OER (\%) } \\
(n=164)\end{array}$ & $P$-value* \\
\hline \multicolumn{5}{|l|}{ Gender } \\
\hline Male & 10.3 & \multirow[t]{2}{*}{$<0.001$} & 9.3 & \multirow[t]{2}{*}{0.007} \\
\hline Female & 18.5 & & 6.2 & \\
\hline \multicolumn{5}{|l|}{ Age (years) } \\
\hline $65-74$ & 16.2 & \multirow[t]{3}{*}{0.38} & 9.6 & \multirow[t]{3}{*}{0.77} \\
\hline $75-84$ & 13.9 & & 8.4 & \\
\hline$\geq 85$ & 13.6 & & 10.0 & \\
\hline \multicolumn{5}{|l|}{ Cultural origin } \\
\hline Flemish & 13.0 & \multirow[t]{2}{*}{0.21} & 7.9 & \multirow[t]{2}{*}{0.98} \\
\hline Walloon & 14.6 & & 7.9 & \\
\hline \multicolumn{5}{|l|}{ Education level } \\
\hline Elementary & 15.7 & \multirow[t]{3}{*}{0.028} & 6.3 & \multirow[t]{3}{*}{0.007} \\
\hline Secondary & 11.5 & & 9.8 & \\
\hline Upper studies & 13.5 & & 11.1 & \\
\hline \multicolumn{5}{|l|}{ Smoking status } \\
\hline Smoker & 11.8 & \multirow[t]{3}{*}{0.001} & 9.3 & \multirow[t]{3}{*}{0.13} \\
\hline Ex-smoker & 6.5 & & 7.4 & \\
\hline Non-smoker & 16.3 & & 6.8 & \\
\hline \multicolumn{5}{|l|}{$\mathrm{BMI}\left(\mathrm{kg} \mathrm{m}^{-2}\right)$} \\
\hline$<25$ & 6.3 & \multirow[t]{3}{*}{$<0.001$} & 13.4 & \multirow[t]{3}{*}{$<0.001$} \\
\hline $25-29$ & 13.2 & & 5.2 & \\
\hline$\geq 30$ & 26.9 & & 4.0 & \\
\hline
\end{tabular}

LER - low-energy reporters; OER - high-energy reporters; BMI - body mass index.

${ }^{*} P$-values derived using Pearson's chi-square test.

confirmed the results of bivariate analysis. After adjustment, high BMI, gender and cultural origin were independently associated with underreporting and low BMI, gender and education level were independent predictors of overreporting (Table 3).

\section{Dietary characteristics of LER and OER}

Table 4 shows the percentage of energy from different nutrients according to category of energy reporting (low, high and accurate). Percentages of energy from protein and carbohydrates were significantly higher in LER, whereas the percentage of energy from fat tended to be lower. The percentage of energy from alcohol was also lower in LER, but not in a significant manner. Conversely, the percentages of energy from protein and carbohydrates were significantly lower in OER than in accurate reporters.

When considering food groups, LER reported significantly lower absolute intakes of all food groups examined, with the exception of fish (Table 5). Using relative (percentage of energy) rather than absolute intake (data not shown), LER reported significantly higher intakes of meat, dairy products, bread, fruit and vegetables, and significantly lower intakes of cheese, chicken and sweets. OER reported significantly higher absolute intakes of bread, cheese, dairy products, meat, fat and sweets (Table 5).

\section{Discussion}

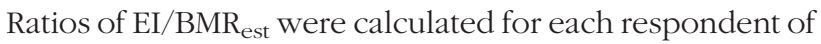
the 'Quality of life after 65' study. The mean (SD) EI/BMR est was 1.37 (0.50), which was below the acceptable limit of 1.53 defined by Goldberg et $a l^{5}$, indicating that energy intake was underreported in the group. The finding of low $\mathrm{EI} / \mathrm{BMR}_{\mathrm{est}}$ in the present study is consistent with other published data using one 24-hour dietary recall ${ }^{15}$.

Using the Goldberg cut-off of EI/BMR est $<0.90$ to classify LER, underreporters accounted for $13.6 \%$ of our study population. The percentage of underreporters observed in this study is consistent with or lower than that in other studies. Direct comparison of the magnitude of underreporting in different dietary studies is difficult because the definition used varies considerably, with cutoffs ranging from 0.9 to $1.55^{15}$. The percentage of subjects who underreported their energy intake varied from 12 to $81 \%$ for men and 11 to $81 \%$ for women ${ }^{15}$. The low percentage of underreporters may be explained by the fact that the Goldberg methodology used in this study provides a conservative estimate of low-energy reporting, because it does not identify those with high energy needs who might be reporting low energy as well. It identifies only

Table 3 Odds of under- and overreporting in the study population

\begin{tabular}{|c|c|c|c|c|c|}
\hline \multicolumn{3}{|c|}{ Underreporting ( $n=1898 ; 287$ LER) } & \multicolumn{3}{|c|}{ Overreporting $(n=1779 ; 163$ OER) } \\
\hline & Adjusted* OR (95\% Cl) & $P$-value & & Adjusted† OR $(95 \% \mathrm{Cl})$ & $P$-value \\
\hline Gender & & & Gender & & \\
\hline Male & 1.00 & & Male & $1.47(1.05-2.06)$ & 0.026 \\
\hline Female & $1.65(1.26-2.15)$ & $<0.001$ & Female & 1.00 & \\
\hline Cultural origin & & & Education level & & \\
\hline Flemish & 1.00 & & Elementary & 1.00 & \\
\hline Walloon & $1.42(1.10-1.83)$ & 0.029 & Secondary & $1.55(1.11-2.18)$ & \\
\hline & & & Upper studies & $1.65(0.90-3.04)$ & 0.026 \\
\hline $\mathrm{BMI}\left(\mathrm{kg} \mathrm{m}^{-2}\right)$ & & & $\mathrm{BMI}\left(\mathrm{kg} \mathrm{m}^{-2}\right)$ & & \\
\hline$<25$ & 1.00 & & $<25$ & $2.38(1.47-3.90)$ & \\
\hline $25-29$ & $2.34(1.60-3.42)$ & & $25-29$ & $1.04(0.63-1.72)$ & \\
\hline$\geq 30$ & $5.17(3.48-7.68)$ & $<0.001$ & $\geq 30$ & 1.00 & $<0.001$ \\
\hline
\end{tabular}

LER - low-energy reporters; OER - high-energy reporters; OR - odds ratio; Cl confidence interval; BMI - body mass index.

${ }^{*}$ Adjusted for gender, cultural origin and BMI compared with those who accurately reported energy intake. Age, smoking and education level were not significant (Hosmer-Lemeshow goodness-of-fit test).

†Adjusted for gender, education level and BMI compared with those who accurately reported energy intake. Age, smoking and cultural origin were not significant (Hosmer-Lemeshow goodness-of-fit test). 
Table 4 Macronutrient intakes of LER, OER and accurate reporters (NLER, NOER)

\begin{tabular}{lccccc}
\hline & LER $(n=293)$ & OER $(n=164)$ & $\begin{array}{c}\text { Accurate reporters } \\
(n=1626)\end{array}$ & $\begin{array}{c}P \text {-value* } \\
\text { LER/NLER }\end{array}$ & $\begin{array}{c}P \text {-value* } \\
\text { OER/NOER }\end{array}$ \\
\hline Protein (\%E) & $19.4(7.1)$ & $13.2(5.6)$ & $16.8(4.8)$ & $<0.001$ & $<0.001$ \\
Fat (\%E) & $32.4(8.9)$ & $36.2(12.9)$ & $36.2(8.2)$ & $<0.001$ & 0.48 \\
SFA (\%E) & $12.7(5.3)$ & $14.4(5.8)$ & $14.5(4.9)$ & $<0.001$ & 0.67 \\
MUFA (\%E) & $11.9(4.3)$ & $13.7(5.6)$ & $13.4(4.1)$ & $<0.001$ & 0.16 \\
PUFA (\%E) & $5.8(3.3)$ & $6.3(4.8)$ & $6.3(3.3)$ & 0.032 & 0.89 \\
Carbohydrates (\%E) & $50.3(51)$ & $40.3(23.2)$ & $45.6(36.8)$ & 0.024 & 0.04 \\
Monosaccharides (\%E) & $17.2(7.7)$ & $14.7(7.8)$ & $17.0(7.4)$ & 0.42 & $<0.001$ \\
Polysaccharides (\%E) & $27.7(7.5)$ & $19.7(8.2)$ & $24.1(7.1)$ & $<0.001$ & $<0.001$ \\
Alcohol (\%E) & $1.9(4.3)$ & $3.7(7.7)$ & $3.0(9.9)$ & 0.05 & 0.39 \\
\hline
\end{tabular}

LER - low-energy reporters; OER - high-energy reporters; \%E - percentage of energy; SFA - saturated fatty acids; MUFA - monounsaturated fatty acids; PUFA - polyunsaturated fatty acids.

Data presented as mean (standard deviation).

${ }^{*} P$-values derived using the Mann-Whitney test.

those persons who are at the extreme end of the distribution and reports intakes that are not feasible to sustain a sedentary lifestyle. Use of the Goldberg method to estimate LER has considerable limitations. In a critical evaluation of the Goldberg technique Black et $a l^{27,28}$ showed that the cut-off assesses overall bias well at group level, whereas the cut-off is limited by low sensitivity and poor specificity at the individual level. So the use of calculated energy requirement, as a proxy, may not be very satisfactory. Without a biomarker, the estimates of rates low- and high-energy reporting may not be very precise. Another factor contributing to imprecision in the estimates is the lack of information on physical activity. As noted by others (e.g. by Black), a measure of PAL is crucial when using a cut-point such as the Goldberg cut-off for the ratio of energy intake to energy expenditure. When the ratio is $\mathrm{EI} / \mathrm{BMR}_{\mathrm{est}}$, with no consideration of PAL some misclassification may occur unless there is little variation in activity levels across the group. We think that assuming an elderly population to be relatively inactive is reasonable.

The present study confirms that under- and overreporting is unevenly distributed in the population. Consistent with other studies, gender ${ }^{8,11-13,15,17,18}$ and $\mathrm{BMI}^{8,11-19}$ were predictors of misreporting. Whereas women were more likely to underreport energy intake, the prevalence of overreporting was higher in men.
As observed in other studies, underreporting was more prevalent among obese people $e^{8,11-19}$. Among normalweight, overweight and obese subjects, the prevalence of underreporting was 6, 13 and 27\%, respectively. Conversely, overreporting decreased from $13 \%$ in normalweight subjects to $4 \%$ in obese subjects.

The present data also indicate that smoking status and education level do not predict underreporting, which is consistent with some studies ${ }^{14,16}$ but not others ${ }^{8,11-16,18,19}$. The relationship between education level and misreporting is complex. Epidemiological studies indicated that underreporting of energy intake was more frequent in subjects with either a low ${ }^{8,19}$ or a high ${ }^{11,18}$ education level. In our study, we found no association between LER and education level. This could possibly be explained by the fact that almost $60 \%$ of the population had a low educational level. On the other hand, in our study overreporting was more likely to occur in more highly educated subjects, which is consistent with other studies ${ }^{18}$.

In agreement with others ${ }^{14}$ we also found a cultural difference in the reporting of nutrient intakes, with the percentage of underreporters being higher among Walloons compared with Flemish. In the Ontario Health Survey, Pomerleau et $a l .{ }^{14}$ found a higher prevalence of underreporting in those born in Asia compared with Canadian-born respondents.

Table 5 Intake of some food groups among LER, OER and accurate reporters (NLER, NOER)

\begin{tabular}{|c|c|c|c|c|c|}
\hline & $\operatorname{LER}(n=293)$ & $\operatorname{OER}(n=164)$ & $\begin{array}{l}\text { Accurate reporters } \\
\quad(n=1626)\end{array}$ & $\begin{array}{l}P \text {-value* } \\
\text { LER/NLER }\end{array}$ & $\begin{array}{l}P \text {-value* } \\
\text { LER/NOER }\end{array}$ \\
\hline Bread $\left(\right.$ g day $\left.^{-1}\right)$ & $108.9(51.2)$ & $243.8(121.1)$ & $163.9(75.2)$ & $<0.001$ & $<0.001$ \\
\hline Cheese $\left(\mathrm{g} \mathrm{day}^{-1}\right)$ & $12.8(21.2)$ & $40.8(52.4)$ & $26.5(34.9)$ & $<0.001$ & $<0.001$ \\
\hline Milk (g day $\left.{ }^{-1}\right)$ & $125.2(133.3)$ & $270.2(250.9)$ & $199.5(202.8)$ & $<0.001$ & $<0.001$ \\
\hline Meat $\left(\right.$ g day $\left.^{-1}\right)$ & $91.1(76.5)$ & $163.5(132.7)$ & $117.7(89.8)$ & $<0.001$ & $<0.001$ \\
\hline Chicken $\left(\right.$ g day $\left.^{-1}\right)$ & $15.0(41.6)$ & $35.6(82.3)$ & $28.9(69.4)$ & 0.004 & 0.22 \\
\hline Fish $\left(\right.$ g day $\left.^{-1}\right)$ & $16.8(46.4)$ & $23.0(68.5)$ & $30.0(71.3)$ & 0.07 & 0.25 \\
\hline Fat $\left(\text { g day }^{-1}\right)^{\prime}$ & $25.1(15.4)$ & $76.1(49.3)$ & $45.1(23.9)$ & $<0.001$ & $<0.001$ \\
\hline Sweets $\left(\right.$ g day $^{-1}$ ) & $17.2(18.2)$ & $50.8(46.7)$ & $32.2(31.1)$ & $<0.001$ & $<0.001$ \\
\hline Fruit and vegetables ( $\mathrm{g} \mathrm{day}^{-1}$ ) & $277.4(171.7)$ & $373.3(233.7)$ & $351.9(209.9)$ & $<0.001$ & 0.08 \\
\hline
\end{tabular}

LER - low-energy reporters; OER - high-energy reporters.

Data presented as mean (standard deviation).

${ }^{*} P$-values derived using the Mann-Whitney test. 
The importance of underreporting depends on the technique used in food data collection. In an evaluation of 37 food intake studies, Black et al. showed that underreporting is more likely to occur when 24-hour recalls are used compared with dietary history and dietary record techniques ${ }^{28}$.

The present data showed that subjects reporting implausibly low energy intake had lower mean intake of fat but higher mean intakes of protein and carbohydrates (expressed as a percentage of energy) than those reporting acceptable energy intake. Similar results have been reported previously showing that underreporters have diets more closely resembling dietary guidelines ${ }^{11,14-19}$. The current results indicate that underreporting affected all consumed food items (in terms of absolute intake). In terms of relative intake, the results show specific underreporting of energy-rich and micronutrient-poor foods such as sweets and overreporting of healthier foods as bread, fruit and vegetables. If this not accounted for, the proportion of the population meeting recommendations may be overestimated. For micronutrients, underreporting might lead to an overestimation of the proportion of the population not meeting certain recommendations. This is illustrated by a Swedish survey ${ }^{17}$.

Given the moderate response rate, we cannot exclude the possibility of bias. As we cannot ascertain how dietary attitudes or psychological characteristics of non-respondents might differ from those of respondents, it is unclear whether and how non-response may have affected our findings. However, comparison of some characteristics (age, sex, education, and some macronutrients collected at the first screening) between respondents and nonrespondents showed no clear differences.

In summary, the results from this study in an elderly population support conclusions from the majority of other studies investigating misreporting in the general population. BMI seemed to be one of the most important factors in underreporting. This calls for to special attention when dietary surveys are performed on obese or lean people. At present, there is still no answer to the question of how to deal with misreporters. In general, it is not possible to exclude underreporters from further investigations. Therefore, it is important to characterise underreporters and keep those characteristics in mind when interpreting the data. The use of relative intakes and adjustment for misreporting may help to reduce bias in associations between food intakes and health outcomes.

\section{Acknowledgements}

The authors would like to thank the dietitians, Mrs M Bellemans, Mrs M De Maeyer and Mrs M Vanderelst, for their important contribution to the fieldwork and the data input. The original survey was financially supported by the National Fund for Scientific Research (fund no. 3.9002.79), the Ministry of Public Health (fund no.
160D1296) and the Institute of Public Health (fund no. 160A8993).

\section{References}

1 Zhang J, Temme EH, Sasaki S, Kesteloot H. Under- and overreporting of energy intake using urinary cations as biomarkers: relation to body mass index. American Journal of Epidemiology 2000; 152: 453-62.

2 Hill RJ, Davies PS. The validity of self-reported energy intake as determined using the doubly labelled water technique. British Journal of Nutrition 2001; 85: 415-30.

3 Trabulsi J, Schoeller DA. Evaluation of dietary assessment instruments against doubly labeled water, a biomarker of habitual energy intake. American Journal of Physiology 2001; 281: E891-9.

4 Subar AF, Kipnis V, Troiano RP, Midthune D, Schoeller DA, Bingham $\mathrm{S}$, et al. Using intake biomarkers to evaluate the extent of dietary misreporting in a large sample of adults: the OPEN study. American Journal of Epidemiology 2003; 158: $1-13$.

5 Goldberg GR, Black AE, Jebb SA, Cole TJ, Murgatroyd PR, Coward WA, et al. Critical evaluation of energy intake data using fundamental principles of energy physiology: 1 . Derivation of cut-off limits to identify under-recording. European Journal of Clinical Nutrition 1991; 45: 569-81.

6 Bingham S. The dietary assessment of individuals: methods, accuracy, new techniques and recommendations. Nutrition Abstracts and Reviews 1987; 57: 705-42.

7 Hebert JR, Clemow L, Pbert L, Ockene IS, Ockene JK. Social desirability bias in dietary self-report may compromise the validity of dietary intake measures. International Journal of Epidemiology 1995; 24: 389-98.

8 Gnardellis C, Boulou C, Trichopoulou A. Magnitude, determinants and impact of under-reporting of energy intake in a cohort study in Greece. Public Health Nutrition 1998; 1: 131-7.

9 Prentice RL. Measurement error and results from analytic epidemiology: dietary fat and breast cancer. Journal of the National Cancer Institute 1996; 88: 1738-47.

10 Paeratakul S, Popkin BM, Kohlmeier L, Hertz-Picciotto I, Guo X, Edwards LJ. Measurement error in dietary data: implications for the epidemiologic study of the diet-disease relationship. European Journal of Clinical Nutrition 1998; 52: $722-7$.

11 Lafay L, Basdevant A, Charles MA, Vray M, Balkau B, Borys $\mathrm{JM}$, et al. Determinants and nature of dietary underreporting in a free-living population: the Fleurbaix Laventie Ville Sante (FLVS) Study. International Journal of Obesity and Related Metabolic Disorders 1997; 21: 567-73.

12 Tomoyasu NJ, Toth MJ, Poehlman ET. Misreporting of total energy intake in older men and women. Journal of the American Geriatrics Society 1999; 47: 710-5.

13 Harrison GG, Galal OM, Ibrahim N, Khorshid A, Stormer A, Leslie J, et al. Underreporting of food intake by dietary recall is not universal: a comparison of data from Egyptian and American women. Journal of Nutrition 2000; 130: 2049-54.

14 Pomerleau J, Ostbye T, Bright-See E. Potential underreporting of energy intake in the Ontario Health Survey and its relationship with nutrient and food intakes. European Journal of Epidemiology 1999; 15: 553-7.

15 Livingstone MB, Black AE. Markers of the validity of reported energy intake. Journal of Nutrition 2003; 133(Suppl.): $895 \mathrm{~S}-920$.

16 Johansson G, Wikman A, Ahren AM, Hallmans G, Johansson I. Underreporting of energy intake in repeated 24-hour recalls related to gender, age, weight status, day of interview, educational level, reported food intake, smoking habits and area of living. Public Health Nutrition 2001; 4: 919-27. 
17 Becker W, Foley S, Shelley E, Gibney M. Energy underreporting in Swedish and Irish dietary surveys: implications for food-based dietary guidelines. British Journal of Nutrition 1999; 81(Suppl.): S127-31.

18 Mendez MA, Wynter S, Wilks R, Forrester T. Under- and overreporting of energy is related to obesity, lifestyle factors and food group intakes in Jamaican adults. Public Health Nutrition 2004; 7: 9-19.

19 Johansson L, Solvoll K, Bjorneboe GE, Drevon CA. Underand overreporting of energy intake related to weight status and lifestyle in a nationwide sample. American Journal of Clinical Nutrition 1998; 68: 266-74.

20 Kornitzer M, Dramaix M. The Belgian Interuniversity Research on Nutrition and Health (BIRNH): general introduction. Acta Cardiologica 1989; XILIV: 89-99.

21 World Health Organization (WHO). Physical Status: The Use and Interpretation of Anthropometry. Report of a WHO Expert Committee. WHO Technical Report Series No. 854. Geneva: WHO, 1995.

22 Voorlichtingsbureau voor de Voeding. Nederlandse voedingsmiddelentabel, druk 32. Netherlands: Gravenhage, 1979.

23 Paul AA, Southgate D. The Composition of Foods, 4th ed. London: The Royal Society of Chemistry, 1980; 297.
24 Schofield WN. Predicting basal metabolic rate, new standards and review of previous work. Human Nutrition. Clinical Nutrition 1985; 39C(Suppl.): 5-41.

25 Black AE, Goldberg GR, Jebb SA, Bingham SA, Livingstone MBE, Prentice AM. Validations of dietary assessment using doubly labelled water. Proceedings of the Nutrition Society 1992; 51: 72A.

26 Black AE, Coward WA, Cole TJ, Prentice AM. Human energy expenditure in affluent societies: an analysis of 547 doublylabelled water measurements. European Journal of Clinical Nutrition 1996; 50: 72-92.

27 Black AE. Critical evaluation of energy intake using the Goldberg cut-off for energy intake:basal metabolic rate. A practical guide to its calculation, use and limitations. International Journal of Obesity and Related Metabolic Disorders 2000; 24: 1119-30.

28 Black AE, Goldberg GR, Jebb SA, Livingstone MBE, Cole TJ, Prentice AM. Critical evaluation of energy intake data using fundamental principles of energy physiology: 2. Evaluating the results of published surveys. European Journal of Clinical Nutrition 1991; 45: 583-99. 